\title{
The Optimizing Roller Spacer Size by Correlation and Regression Analysis
}

\author{
Arvita Emarilis Intani \\ arvita@pelitabangsa.ac.id \\ University Pelita Bangsa, Indonesia
}

\begin{abstract}
The Spacer is one of part roller machine which the functions to adjustment size of synthetic rubber to obtain suitable size based on standard specifications. The problems are various spacer size to be used mass production which it cause to variation size of rubber and consequences to product result. To analizing problem, there are good chance to apply mathematical solution. Problem solving using correlation and regression analysis enable determining the relationship between the independent factors and the dependent response through defined relationship estimates, optimizing the sizes, regression functions, predicting and simulating result. Despite there are many regression analysis, Linear regression analysis is the most widely used of all statistical technique. The application to analysis the problem with correlation and linear regression calculation in Minitab.
\end{abstract}

Keywords: Correlation, Linear Regression, Optimizing Solution.

\section{Introduction}

In the manufacturing industry mainly in producing products such as paper, fabric, plastic and rubber, one of the machines used is Roller or Calendar roll. In the paper industry, the machine serves to smooth and compress materials during production by passing a single continuous sheet through several pairs of heated rolls. While in the rubber industry, this machine is used to ;

a. Make a long and wide rubber compound (Sheet compound) thick and thin

b. Overlay rubber compound on woven surface (coating)

c. Inserting rubber compound into woven fabric that has been friction or woven rubber (skimming)

d. Double-layer rubber sheets or rubberized weave (doubling)

e. Making a rubber compound form (shaping) on the surface of the roller (profiling)

In this study will observe the variation in size resulting from the roller process. Determination of the spacer roll part in the Roller, where the spacer determines the variation in size produced in forming the rubber compound according to the specifications requested during production. Variations in results often occur during the initial trial of production, with many experiments to get the appropriate size of the spacer, as a result of which it takes a long time and the quality of rubber becomes less good due to the heat that arises in the process. If at 
the time of the production process, the size of the spacer is not correct so that the result of rubber size does not match the specifications requested to cause the product to have excess rubber residue can even occur defects. So in this study will use statistical methods to get the correct spacer size, namely by analyzing correlation and linear regression in Minitab.

\section{Research Methodology}

Statistical methodology consists of four main stages, namely data collection, presentation, analysis and interpretation of data or numerical methods, which is a way to decipher the facts and interpretation. The statistical methodology not only detects the general characteristics of variable phenomena, but can also detect regularity in the tendencies of a phenomenon. One of the methods in statistical analysis used is relationship problems, links (correlations) and conclusions based on samples. This method is included in the field of analytical statistics (Zvizdojević, 2015)

Statistical analysis is one of the most useful sources of measurement variables to test hypotheses about the association between two or more variables, evaluation of numerical values of expressed functions, as well as to verify survey results, compare actual and assumed status (Pejanovic, 2007). One methodolgy used in statistical science is correlation analysis. Correlation Analysis is a study that discusses the degree (How strong) the relationship between two or more variables. The measure of the degree relationship is called the correlation coefficient is a number that indicates the direction and strength of the relationship between two or more variables, i.e.

a. Independent Variable, Notation: X, i.e. Variables whose existence is not affected by other variables

b. Dependent Variable, Notation: Y, i.e. Variable whose existence is influenced by other variables

For correlation analysis expressed in the form of positive or negative relationships.

a. The direction of a positive relationship means:

1) If the value of the variable is increased, it will increase the value of the other variables

2) If the value of the variable is lowered, it will decrease the value of the other variables

b. The direction of the negative relationship means:

1) If the value of the variable is increased, it lowers the value of the other variables

2) If the value of the variable is lowered, it will increase the value of the other variables

c. No correlation or very weak correlation

This correlation occurs when both variables (X and $\mathrm{Y}$ ) do not indicate a linear relationship.

d. Perfect correlation

Perfect correlation usually occurs when the increase / decrease of variable $\mathrm{X}$ is always proportional to the increase / decrease of variable Y. If depicted with a point chart or scatter chart (Scatter Plot), the dots line up to form a straight line, with almost no scattering. 
Then the second analysis is linear regression analysis. Regression analysis is used to $p$ redict the value of dependent variables based on the value of at least one independent variable and confirm the impact of changes independent variables (Gap spacer roll to be used in Roller machine) on dependent variables (Thickness that corresponds to the standard specifications of the product).

By collecting data as many as 30 samples from existing product specification then using correlation and regression analysis methods, as well as implementing the predictions obtained. This research is about the problem of predicting gap spacer roll used to produce thickness in accordance with the standard specifications of the item. The research is in the form of analyzing the relationship between gap spacer roll to thickness rubber and using regression analysis for the right variables in determining the gap of the spacer roll.

By collecting data as many as 30 samples from existing product specification then using correlation and regression analysis methods, as well as implementing the predictions obtained. This research is about the problem of predicting gap spacer roll used to produce thickness in accordance with the standard specifications of the item. The research is in the form of analyzing the relationship between gap spacer roll to thickness rubber and using regression analysis for the right variables in determining the gap of the spacer roll.

\section{Result and Discussion}

From a pre-existing sample of 30 samples, it can help to see the correlation between Gap spacer Roll and Thickness:

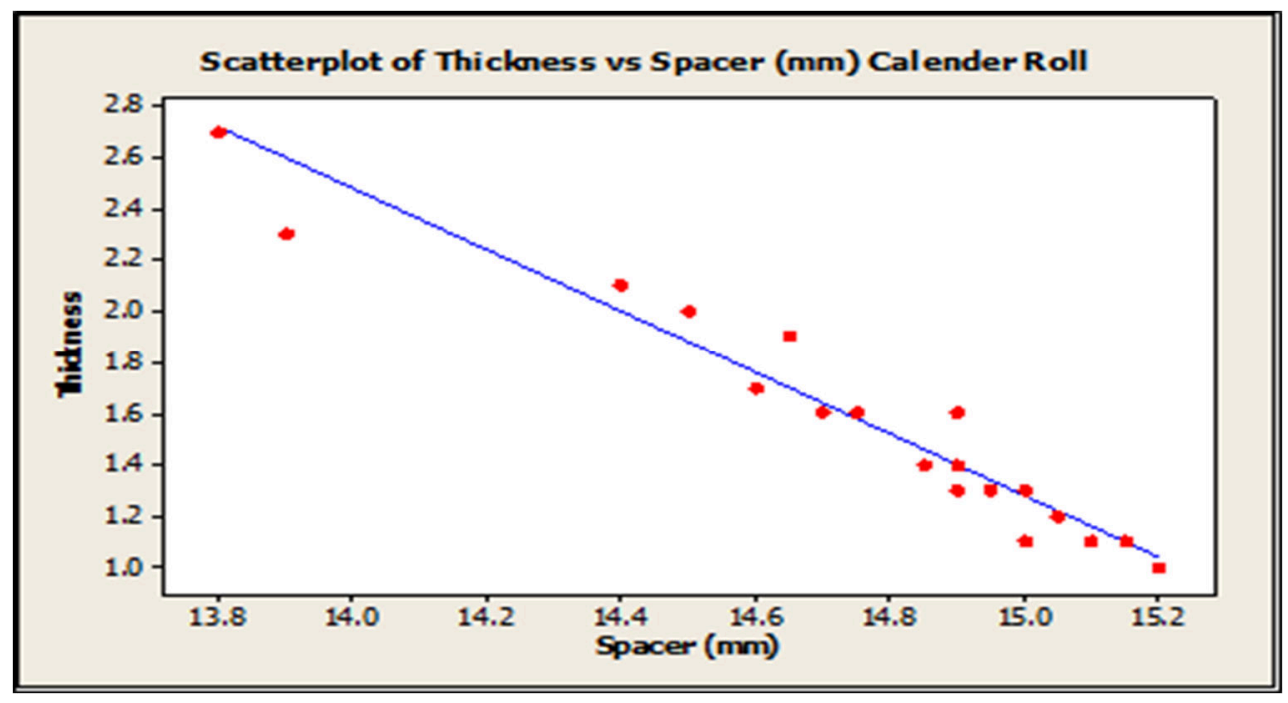

The correlation value between spacer and thickness of -0.96 is close to the optimal value of correlation -1, with correlation coefficient is negative, meaning there is a strong relationship between the two variables is negative or inversely proportional. The larger the gap spacer makes the thinner the thickness size. 
After determining the correlation coefficient value and the direction of the correlation, then use regression analysis to predict the gap spacer value needed to produce the required thickness of the product specification. below:

The following calculations using minitab, obtained the results of regression analysis

\begin{tabular}{|c|c|c|c|c|}
\hline Predictor & Coef & SE Coef & $\mathrm{T}$ & $P$ \\
\hline$\overline{\text { Constant }}$ & 19.2304 & 0.9613 & 20.00 & 0.000 \\
\hline Spacer (x) & -1.19668 & 0.06508 & -18.39 & 0.000 \\
\hline
\end{tabular}

The regression equation is $(\mathrm{y})=19.2-1.20(\operatorname{spacer}(\mathrm{x}))$

A value of 19.2 is the estimated average value of $y$ when the value of $x$ is zero, meaning there is no need to use a spacer when producing a thickness of $19.2 \mathrm{~mm}$. While the value of 1.20 measures the estimated change in the average value of thickness as a result of a one size change in spacer, meaning that the value of 1.20 states that the average value of thickness is reduced by $-1.20 \mathrm{~mm}$ on the average of each spacer size change used. So if there is a new product specification, it can calculate the estimated spacer that can be used in accordance with the equation of the regression estimate.

\section{Conclusion}

Based on the correlation and linear regression analysis, the correlation between thickness and spacer roll has strong correlation, the value is -0.96 , is close to the optimal value of correlation -1 , between the two variables is negative or inversely proportional. The larger the gap spacer makes the thinner the thickness size.

The regression equation is thickness $(\mathrm{y})=19.2-1.20($ spacer $(\mathrm{x}))$, is an estimate of the mean $\mathrm{y}$ value if the $\mathrm{x}$ value is zero, meaning there is no need to use a spacer when producing a thickness of $19.2 \mathrm{~mm}$. While the value of 1.20 measures the estimated change in the mean thickness value as a result of a change in the size of the spacer by one size, meaning that the average thickness value decreases by an average of $-1.20 \mathrm{~mm}$ respectively.

\section{References}

[1] Bass, Issa: Six Sigma Statistics With Excel and Minitab, first Edition, McGraw-Hill, Inc.

[2] Gaspersz, Vincent: Total Quality Management, Seventh Edition, Vinchristo Publication, Bogor.

[3] Grant, Eugene L. and Leavenworth, Richard S.: Statistical Quality Control, Sixth Edition, McGraw-Hill, Inc.

[4] Pejanovic, R.: Some methodological phases and procedures in economy (and agricultural economy), Yearbook of scientific papers, Vol. 31, no. 1, pp. 174-186, University of Novi Sad - Faculty of Agriculture (2007)

[5] Pietrzak, Michael B.: The Modifiable Areal Unit Problem - Analysis of Correlation and Regression, Equilibrium Vol. 9 Issue 4, Nicolaus Copernicus University, Poland (2014)

[6] Sudjana: Statistical Methods, first Edition, Tarsito Publisher, Bandung. 
[7] Supranto, J.: Statistical Theory and Applications, Seventh Edition, Erlangga Publisher, Jakarta

[8] Zvizdojević, J. and Vukotić, M.: Application of statistical Methods in Analysis of Agriculture - Correlation and Regression Analysis. DOI: Agriculture \& Forestry, Vol.61 Issue 1: 309-324, Podgorica (2015) 